\title{
Habitus e desenvolvimento profissional da docência: um estudo no curso de Pedagogia
}

\author{
Giselly Cristini Mondardo Brandalise
}

Adriane Knoblauch

\section{Resumo}

Este artigo trata sobre os processos de desenvolvimento profissional da docência de três alunas do curso de Pedagogia de uma universidade pública do estado do Paraná, em pesquisa realizada entre os anos de 2013 a 2014. Possui como base teórico-metodológica os estudos sociológicos de Pierre Bourdieu, bem como as discussões sobre desenvolvimento profissional docente presentes na literatura de Marcelo Garcia (1999, 2009). Foram constatadas três categorias que atuaram como orientadoras na escolha do referido curso e de novas aprendizagens: afetiva, mista e transformadora. A análise de dados indica que a aprendizagem da docência na formação inicial está intimamente ligada às relações estabelecidas no decorrer da socialização primária e o primeiro ciclo de escolarização.

Palavras-chave: Desenvolvimento profissional docente. Habitus. Formação inicial. Pedagogia. 


\title{
Habitus and professional development of teaching: a study in the Pedagogy course
}

\author{
Giselly Cristini Mondardo Brandalise \\ Adriane Knoblauch
}

\section{Abstract}

This article deals with the professional development processes of teaching by three students of the Pedagogy course of a public university of the state of Paraná in research conducted between 2013 and 2014. It has as theoreticalmethodological basis the sociological studies of Pierre Bourdieu, as well the discussions about professional development of teaching present in the literature of Marcelo Garcia (1999, 2009). Three categories that served as guiding the choice of that course and new learning were found: affective, mixed and transformative. Data analysis indicates that teaching learning in initial formation is closely linked to the relationships established during primary socialization and the first step of schooling.

Keywords: Professional development of teaching. Habitus. Initial formation. Pedagogy. 


\section{Introdução}

O ingresso no ensino superior é um momento marcante na vida dos indivíduos. Identificar e definir uma área de interesse para atuação não é uma tarefa fácil, pois, para a maioria das pessoas, essa decisão irá fundamentar e desencadear outras ações que serão norteadoras de suas vidas, no que tange à carreira profissional.

Optar pelas licenciaturas significa que o indivíduo se identificou com certos conhecimentos, normas e valores relativos à docência nos momentos que antecedem o ingresso formal à universidade.

Marin (1996) e Mizukami (1996) já apontaram que o aprendizado da docência ocorre antes mesmo do ingresso na formação inicial em cursos de licenciatura, destacando a necessidade de uma concepção mais ampliada sobre a formação docente. Atualmente, há um conjunto de autores que definem a formação docente ampliada a partir do conceito de desenvolvimento profissional docente (MARCELO GARCIA, 1999; 2009). Nessa perspectiva, os sentidos e saberes adquiridos ao longo da carreira vão muito além de ensinamentos teóricometodológicos sobre a educação e ocorrem em diversos períodos da vida dos indivíduos imersos nessa realidade, através de um processo heterogêneo e social.

O recorte apresentado por este trabalho ${ }^{27}$ se refere a dois momentos definidos pela teoria de Marcelo Garcia (1999): a fase do pré-treino - momento em que os indivíduos operam ainda enquanto alunos da educação básica - e a formação inicial - o ingresso formal na universidade. Parte-se da premissa de que, na fase do pré-treino, o indivíduo, como discente da educação básica, incorpora ações e concepções de seus professores, ainda que não intencionalmente. Com esses conhecimentos, que se entrelaçam a outros fatores de influência de seu contexto sócio-econômico-cultural, os discentes ingressam na licenciatura, na fase da formação inicial.

O contato com novos conhecimentos advindos da universidade irá influenciar diretamente sobre os princípios com os quais o indivíduo se apresenta nesse espaço. Dessa forma, o conceito de habitus explica como isso ocorre: os princípios são construídos e constituídos com base em representações e experiências ocorridas a partir de disposições já existentes, que funcionam como uma espécie de referência para o desenvolvimento de ações do sujeito. Em movimentos contínuos e, por vezes, divergentes, as novas informações serão filtradas e irão interagir com as referidas disposições, gerando, então, uma matriz de esquemas e percepções para os seus atos (BOURDIEU, 2003).

A partir disso, o objetivo deste artigo é demonstrar como as disposições presentes no habitus de três alunas de um curso de Pedagogia, aprendidas no decorrer da trajetória escolar, marcam e/ou expressam a aprendizagem da docência no âmbito da formação inicial, de modo

${ }_{27}$ Dissertação apresentada em 2016 com apoio da CAPES. 
a compreender como as disposições adquiridas na fase pré-treino se relacionam com os novos conhecimentos incorporados e atuam como orientadoras de novas aprendizagens relacionadas à docência.

Os dados foram coletados em uma universidade pública do estado do Paraná, por meio de entrevistas semiestruturadas que ocorreram ao longo de 2013 e 2014, gravadas e, posteriormente, transcritas, após a assinatura do termo de consentimento livre e esclarecido, tendo como referencial teórico-metodológico os ideais de Pierre Bourdieu e analisados também sobre os preceitos da Análise de Conteúdo, postulados por Bardin (2011).

Dessa forma, inicialmente, serão apresentadas reflexões sobre os conceitos orientadores da análise. Em seguida, os caminhos metodológicos serão explicitados. Por fim, serão apresentados os dados e análises referentes ao perfil e aprendizagens da docência, incorporados pelas alunas em questão, bem como notas conclusivas.

\section{Notas sobre socialização, habitus e desenvolvimento profissional docente}

De acordo com Berger e Luckmann (1985), o processo de socialização ocorre a partir da constituição da sociedade e da vida civilizada, já que apenas um indivíduo não se desenvolve, implanta, ou integra uma sociedade sozinho. De acordo com o autor (1985) estar em sociedade significa fazer parte de uma esfera social, do mundo objetivado.

Integrar uma esfera social significa, portanto, estar envolto por relações sociais. É característico da sociedade e de seus grupos possuir diretrizes de vida próprias, ou seja, suas leis, seus costumes, enfim, os mais diversos símbolos que orientam o seu funcionamento, sua cultura $^{28}$.

Para alguns autores, como Forquin (1993), a ideia de cultura está intrinsecamente relacionada à educação. Em sua perspectiva, na configuração que desempenha na sociedade, a educação não se justifica e não pode ser pensada sem a cultura e vice-versa.

Acolhendo a perspectiva de que a sociedade condiciona e adapta sua própria cultura de acordo com os indivíduos que a compõem, Berger e Luckmann (1985) detalham o processo de socialização como a incorporação duradoura das formas de sentir, pensar e agir do próprio grupo de origem.

Para Setton (2011), a socialização é uma área de investigação caracterizada pelo estudo das relações indissociáveis entre indivíduo e sociedade. Possui uma dimensão produtora, difusora e reprodutora, focalizada nas instituições como formadoras de cultura e formas de transmissão dos valores de um grupo social, bem como processos de incorporação dos indivíduos ao longo de suas vidas. Esse processo tem início por meio dos contatos que a

${ }^{28} \mathrm{O}$ conceito de cultura está sendo entendido aqui por um conjunto de símbolos que operam como disposições ou pré-disposições de habitus e se apresentam de maneira formal ou informal, objetivos ou abstratos, pela família, escola e outras autoridades (SETTON, 2002).

ISSN 2526-2882 
criança estabelece a partir de seu nascimento com o meio e com as pessoas próximas à realidade que lhe está posta. É na socialização primária que ela começa a se perceber como um agente social, compreendendo a existência do próximo e internalizando condicionantes e matrizes culturais que serão referências para sua vida social (BERGER; LUCKMANN,1985).

Atualmente, é comum que a inserção à vida escolar caminhe e se constitua ao lado da socialização primária, visto que costuma ser o próximo contato formal que o agente social estabelece com o mundo, sobretudo em uma sociedade em que boa parte dos pais e/ou responsáveis pelas crianças trabalha em período integral.

Assim como a família, a escola também possui sua própria cultura e socializa aqueles que por ela passam. Por um lado, cumpre e apresenta as formas de ensinar e aprender dos envolvidos por meio do currículo prescrito e oficial. Por outro lado, as relações que se situam no interior da escola transmitem as formas de incorporação destas questões (JULIA, 2001). De todo modo, a socialização escolar difere de outros tipos de socialização, por ser concebida pelos pais como indispensável para a formação e o desenvolvimento de seus filhos (KNOBLAUCH, 2008).

Nunes (2001) afirma que à escola cabe a função de determinar, de forma ampla, a ordem social, uma vez que, para além dos conteúdos, os sujeitos incorporaram formas de raciocínio, bem como compreensões a respeito de formas de aprendizagem e de ensino. Também nesse espaço, ainda que inconscientemente, os sujeitos descobrirão a existência de relações de poder e normas de comportamento das classes dominantes, algo que se justifica através de uma arbitrariedade cultural imposta a longos tempos.

Neste contexto, se faz necessário pensar e refletir sobre a constituição da formação docente no Brasil. De acordo com Tanuri (2000), os primeiros professores desta pátria, os jesuítas, atuavam, sobretudo, com a população indígena e escrava em um ensino voltado à instrução moral, intimamente ligado aos ideais religiosos característicos da teologia.

Mais tarde, por volta de 1830, quando a chegada da escola normal no Brasil, o ensino tornou-se responsabilidade do Estado. O número de vagas para a escolarização foi rapidamente ampliado e a demanda por profissionais da área também. Por conta dessa problemática, valores difundidos pelos jesuítas - amor, afeto, bondade, paciência, entre outros - foram elencados como características fundamentais e que supririam o que a profissão necessitava (TANURI, 200o), dando início ao processo de feminização do magistério. Sobre este último, baseada nos estudos de Bourdieu, Knoblauch (2008) compreende que tal fato decorre de lentos e contínuos articulados processos de socialização na esfera social que emergem na sociedade como uma forma de identificar e diferenciar a função de homens e mulheres no interior da família, mas que também acabam por se instalar na cultura escolar.

Além disso, outras características veiculadas trataram de demarcar aspectos culturais na área da educação: a escola, sendo operacionalizada a partir da transmissão de conteúdos 
voltados à cultura dominante e a religião, no monopólio do poder, pontuando e sustentando as questões fundamentais para os cristãos. Esta breve síntese mostra que os conjuntos de saberes e valores das instituições detentoras da educação formal (escola e igreja) eram e estavam muito próximos, indicados naquele tempo como suficientes para socializar uma pessoa, e neste caso, também uma profissão. Ao longo de um extenso período, a escola e a religião, de maneira imbricada, cumpriram o papel de socializar e inserir um agente à esfera social (TANURI, 2000).

Bourdieu (2003) compreende que as estruturas forjadas na sociedade ocorrem a partir da relação dialética entre essas estruturas e as disposições que dela decorrem e, dessa forma, tendem a ser reproduzidas continuamente por meio do habitus. Este seria, como definido pelo o autor, o processo de interiorização da exterioridade e exteriorização da interioridade. Nesse sentido, a construção da identidade está sendo encarada, nessa pesquisa, como o processo de socialização por meio do habitus $e$, nesta perspectiva, como já explicitado anteriormente, compreende-se, então, que as vivências do indivíduo se instalam e se ressignificam quando submetidas às condicionantes sociais e trajetórias particulares e subjetivas de sua própria vida (SETTON, 2002; 2011).

No tocante à configuração da sociedade nos últimos tempos, algumas mudanças marcantes surgem a partir da década de 70 com a introdução tecnológica no Brasil: As mídias ${ }^{29}$ e em especial a TV, o rádio e a internet, emergem e contribuem para com a construção de múltiplas possibilidades de desenvolver e estruturar identidades. Dentro da perspectiva de pluralidade de valores e referências identitárias, Setton (2002) vislumbrou o conceito de habitus com disposições híbridas, fazendo referência à contemporaneidade que possibilita ao indivíduo mesclar diversas matrizes de disposições. Nas palavras da autora,

[...] no contexto atual, cada uma das instâncias formadoras desenvolve campos específicos de atuação, lógicas e valores éticos e morais distintos, considera-se ainda que são os próprios indivíduos que tecem as redes de sentido que os unificam em suas experiências de socialização (SETTON, 2002, p.107).

Diferente da configuração de sociedade tradicional, na sociedade contemporânea o caminho a seguir não precisa se definir apenas através de vivências próximas no tempo e espaço, mas pode contar com modelos e referências fisicamente longilíneas e dispersas (SETTON, 2002). É possível concluir, então, que esta nova forma de encarar a sociedade possibilita ao agente social o contato com múltiplas instituições heterogêneas, por vezes

29 Entendendo por mídias "a produção cultural, material, tecnológica e simbólica divulgada pelo conjunto de instituições da indústria editorial, fonográfica, televisiva, radiofônica, cinematográfica e a publicidade que possibilita a maior circulação de referências de estilos identitários" (SETTON, 2008, p.21).

ISSN 2526-2882 
conflitantes, para a estruturação e reestruturação de seus ideais, de seu habitus e de seu posicionamento nos campos.

Sobre os campos, Bourdieu (2004) define o conceito como determinados espaços em que indivíduos e instituições se posicionam ao mesmo tempo em que travam embates de acordo com os princípios que os regem para melhor dispor em seu interior. Suas posições variam conforme as disposições de capitais específicos, fundamentalmente os capitais econômicos, culturais, sociais e simbólicos que estão em movimento constante pelas disputas de legitimação e controle de acordo com suas próprias regras e leis de funcionamento.

Para tanto, compreende-se que o processo de socialização é um processo de mão dupla, de construção e reconstrução de relações subjetivas, que não são intencionais, com as condições objetivas. Ou seja, a socialização é o resultado da relação dialética entre as condições objetivas e as disposições já incorporadas que se reestruturam ou se mantém de acordo com a posição ocupada no espaço social.

Neste sentido, parece coerente refletir sobre a formação docente de maneira ampliada. Estudos clássicos como o de Lortie (1975), bem como aqueles mais atuais, como os de Marcelo Garcia (1999; 2009) e Nunes (2001), indicam que a decisão de se tornar professor pode possuir raízes nas vivências da educação básica e, especialmente, a convivência com os docentes presentes nesta trajetória.

Para Nunes (2001), os professores da educação básica se tornam, para os alunos, referência de ações e valores e, dessa forma, atuam como socializadores. Durante o processo de socialização dos agentes, as representações dos docentes passam por avaliações críticas sobre essas condutas. Os alunos, ainda que de forma inconsciente, irão incorporar ou negar essas disposições (NUNES, 2001). Ao ingressar na carreira docente, as representações de antigos professores podem servir, muitas vezes, como orientadoras das práticas desenvolvidas inicialmente por estes futuros professores.

Na perspectiva de Marcelo Garcia (1999), ao longo da formação inicial, há um composto de ideias e critérios fundamentados pela reflexão e avaliação que serão, futuramente, aperfeiçoados mediante interação com os alunos compondo, assim, um processo de evolução profissional constante. Criam-se redes de relações que identificam os sujeitos de forma recíproca, por meio de interiorizações e exteriorizações entre os agentes e o meio onde estão alocados.

Para Pryjma (2009), a profissionalização e a construção da profissionalidade envolvem vários aspectos da profissão em si e, consequentemente, apresentam a necessidade de conhecer, de forma objetiva - aspectos externos à profissão - e subjetiva - vivências diárias de um profissional -, as interfaces do trabalho e as relações estabelecidas com a sociedade. Este exercício implicaria na transformação do indivíduo que dialoga com a realidade e suas transformações. 
Dessa forma, entende-se, aqui, o desenvolvimento profissional da docência como a incorporação de valores, conhecimentos e normas que acontecem no decorrer do desenvolvimento da profissão, entrelaçando-se com a trajetória de vida dos sujeitos e que ocorre de maneira longa, lenta e contínua (MARCELO GARCIA, 1999) em diferentes espaços, com base no compromisso individual e institucional (MARCELO GARCIA; PRYJMA, 2013).

\section{Caminho metodológico}

Este trabalho parte de uma pesquisa longitudinal que ocorreu em dois momentos. Inicialmente, nos anos de 2012 e 2013, foram aplicados questionários aos ingressantes do curso de Pedagogia em uma universidade pública do estado do Paraná. A partir do pressuposto teórico-metodológico de Pierre Bourdieu (2011) e com objetivo de traçar um mapeamento do perfil geral desses estudantes, o questionário continha questões sócio-econômico-culturais. A intenção desse mapeamento foi elucidar e trazer à tona facetas de habitus do público alvo, na tentativa de identificar as disposições para a docência que levaram as alunas a escolherem este curso de graduação.

Para a interpretação dos dados, além dos pressupostos praxiológicos de Bourdieu (2001), foram considerados os princípios da Análise de Conteúdo, de Bardin (2011). A partir da pré-análise, foi possível definir três categorias recorrentes fundamentadas em diferentes aspectos que direcionavam o público ao curso de licenciatura em Pedagogia. Em um universo de noventa ingressantes, quarenta e quatro pessoas apresentaram justificativas para a escolha da docência, que envolviam questões orientadas pela afetividade, ou seja, afirmavam gostar de criança, ou, ser membro de uma família de professoras, com o intuito de ajudar o próximo; vinte ingressantes definiram sua escolha para a docência a partir de ideais orientados para a transformação social; e, por fim, vinte e seis pessoas apresentavam justificativas mistas, mesclando essas duas motivações, tanto o ideal afetivo, como o ideal voltado à transformação da educação, conforme sintetizado no quadro 1.

Quadro 1: Motivações para a docência

\begin{tabular}{|c|c|c|c|c|}
\hline Motivações & Afetividade & Transformação & Mista & Total \\
\hline $\begin{array}{c}\text { Número de } \\
\text { ingressantes }\end{array}$ & 44 & 20 & 26 & $\mathbf{9 0}$ \\
\hline
\end{tabular}

Fonte: Dados da pesquisa, 2016.

Com o intuito de esclarecer melhor esta relação com os fatores que diferenciavam as disposições à escolha do curso e a relação com o aprendizado da docência, é que se deu início a um segundo momento da pesquisa, já em 2013. Para tanto, foi enviado um e-mail aos estudantes que responderam o questionário anteriormente. Uma aluna de cada grupo/categoria descrito acima foi selecionada, sendo o critério de seleção dos sujeitos a escolha de alunas que responderam o e-mail e que possuíam disponibilidade de horário para a realização das entrevistas. A hipótese a ser verificada foi a existência de relações entre a 
motivação pela docência e a forma como a qual a aprendizagem ocorreria no decorrer da formação inicial.

As entrevistas aconteceram em dois períodos: em outubro de 2013, com foco nas vivências da fase pré-treino, ou seja, anterior ao ingresso à universidade, e em outubro de 2014, com foco na formação inicial, considerando o fato de que, naquele momento, as participantes já cursavam o terceiro ano do curso e já haviam cumprido um percurso significativo para a articulação de distintas aprendizagens. A transcrição das entrevistas ocorreu à medida que foram realizadas, a fim de evitar falhas que comprometessem a validade da coleta, contribuindo, assim, para a compreensão mais profunda dos dados, conforme orientações praxiológicas de Bourdieu (2011). Além disso, atuaram também como orientadoras as discussões sobre categorização presentes na literatura de Bardin (2011), considerando o inventário, no sentido de isolar os elementos, e a classificação, para organizá-los.

Na sequência, serão apresentados dados sobre as estudantes em questão, bem como reflexões sobre a maneira pela qual as agentes discorreram sobre suas trajetórias na educação básica, ao mesmo tempo que incorporaram elementos do saber docente e, por meio da formação inicial, encontravam-se em processos de ressignificação desses saberes. Em conformidade às orientações da legislação sobre ética em pesquisa envolvendo seres humanos, obteve-se a ciência da utilização dos dados das alunas convidadas para a participação da pesquisa através da assinatura do termo de livre consentimento. A fim de preservar a identidade das colaboradoras, foram utilizados pseudônimos para identificá-las.

\section{As agentes e suas disposições prévias}

Thaís, Sara e Priscila demonstraram possuir, respectivamente, visão afetiva, mista e transformadora como justificativa para a escolha do curso. Foi possível observar semelhanças nas disposições familiares e econômicas: são jovens na faixa etária de 20 anos, solteiras, sem filhos e com núcleos familiares pequenos, todas com apenas um(a) irmão(ã). As duas primeiras residentes em Curitiba-PR, em bairros periféricos e distantes do centro da cidade, e a última em uma cidade desta região metropolitana. Frequentaram colégios públicos na maior parte da educação básica ${ }^{30}$. Declararam renda familiar entre dois e quatro salários mínimos, com apenas uma pessoa contribuinte para a constituição destes rendimentos: Thaís, a mãe; Sara e Priscila, os pais.

Sobre isso, são filhas de pais que não realizaram a educação superior, mas valorizam o sistema escolar e entendem a escola não só como uma instituição com o objetivo escolarizador, mas, socializador, já que opera, também, como uma instituição disciplinadora. Neste sentido, o curso de Pedagogia não só oferece um fácil acesso pela baixa concorrência no

30 Apenas Sara declarou frequência em escolas particulares em alguns períodos de sua escolarização. ISSN 2526-2882

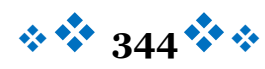


momento do ingresso ${ }^{31}$, mas atua como mecanismo de reversão externado em forma de gratidão, uma vez que proporciona um avanço na trajetória escolar das alunas que ascendem às condições sociais originárias por meio do acesso ao meio acadêmico, uma vez que são as primeiras de suas famílias a ingressarem no Ensino Superior. Ou seja, são pais que veem na escolarização de suas filhas chances de ascensão econômica e social.

Embora com situações de vivências diferentes, as alunas receberam informações de cunho escolar antes mesmo do ingresso formal à escolarização: Thaís possuía uma convivência muito próxima com a irmã mais velha, alfabetizadora; Sara recebeu ensinamentos autônomos e constantes, por parte de sua mãe; e Priscila, acompanhava a irmã à escola no meio rural quando criança por vontade própria, mesmo sem a idade mínima para o ingresso à educação formal. Sendo o habitus familiar o princípio para a estruturação das experiências escolares, e no âmbito particular, de recepção e incorporação de mensagens pedagógicas (BOURDIEU, 2001), as primeiras boas experiências com a cultura letrada das colaboradoras surgem como uma base concisa para estabelecer suas primeiras raízes identitárias com o mundo social. Ainda que seja um período precoce para acusar escolhas para a docência, observa-se a existência de uma gênese das disposições, isto é, formas geradoras da constituição de elementos do habitus, considerando que o mesmo se constitui de estruturação em estruturação (BOURDIEU, 2003), podendo caracterizar o impulso inicial da disposição docente no interior da socialização primária.

Admitindo-as como integrantes de uma mesma fração de classe, ou seja, com habitus que, por um lado, produzem elementos de disposições bastante semelhantes, entende-se, concomitantemente, que as agentes partem de diferentes trajetórias de socialização. Thaís e Sara com relatos de caminhos escolares turbulentos e Priscila com declarações que demonstram poucas oscilações (Quadro 2).

Quadro 2: Trajetórias de socialização

\begin{tabular}{|c|c|c|c|}
\hline Alunas & Thaís & Sara & Priscila \\
\hline $\begin{array}{c}\text { Relatos } \\
\text { escolares }\end{array}$ & $\begin{array}{l}\text { Nessa época, o ensino de lá } \\
\text { (se referindo a mudança } \\
\text { familiar para outro estado) } \\
\text { era muito diferente daqui eu } \\
\text { tava no auge (sic) aqui, né, eu } \\
\text { sabia ler e escrever, eu decaí } \\
\text { muito, minha autoestima } \\
\text { baixou muito com relação ao } \\
\text { estudo nesses três anos. Era } \\
\text { uma escola bem tradicional, } \\
\text { escrevia muito no caderno, } \\
\text { não tinha algo assim, de } \\
\text { diferente, era bem } \\
\text { tradicional. }\end{array}$ & $\begin{array}{l}\text { Foi difícil para mim (sobre os } \\
\text { anos inicias do ensino } \\
\text { fundamental), eu mudei de } \\
\text { escola, sofri bullyng de um } \\
\text { menino [...] Eu sempre fui } \\
\text { sozinha, né, eu era aquela } \\
\text { menina que era quietinha, } \\
\text { que era aplicada, que só tinha } \\
\text { amigos perto da prova, então } \\
\text { assim, eu me sentia muito } \\
\text { excluída. }\end{array}$ & $\begin{array}{l}\text { E eu me sentia muito bem, } \\
\text { porque parecia mais que a gente } \\
\text { ia lá pra (sic) brincar do que pra } \\
\text { (sic) estudar na verdade, então } \\
\text { era um espaço gostoso, porque } \\
\text { eram muito poucos alunos e a } \\
\text { gente conseguia fazer } \\
\text { brincadeiras, conseguia ficar } \\
\text { junto [...]. Então são lembranças } \\
\text { boas, porque atrás da escola, } \\
\text { principalmente tinha bastante, é, } \\
\text { ambiente aberto, pra gente } \\
\text { correr, brincar, tinha árvore. }\end{array}$ \\
\hline
\end{tabular}

Fonte: Dados extraídos das entrevistas realizadas em 2014.

${ }^{31}$ No referido ano de ingresso das alunas em questão à universidade, a instituição, que ainda operava com o processo seletivo por meio do vestibular, divulgou a concorrência entre os inscritos abaixo de três pessoas por vaga, em dois turnos de oferta. 
A seguir, serão apresentados dados das alunas em suas respectivas seções.

\section{Ideologia do dom: Thaís}

A docência, no caso de Thaís - integrante do grupo afetivo -, revelou-se naturalmente como um dom (sic): vem de uma família de professoras que acredita possuir esta característica como missão. De acordo com Bourdieu (2007a), a ideologia do dom natural surge como forma de atestar a fé na capacidade de uma pedagogia racional, que tem por objetivo diminuir os esquemas práticos de familiaridade à regras codificadas, ou seja, o agente exclui a primordialidade da experiência e adquire prazer sem conceituá-la. Aliado à aparente disposição da família, a aluna sente-se agraciada por forte afetividade por parte de sua primeira professora, a irmã mais velha, conforme seu relato exposto no quadro 3 , a seguir:

Quadro 3: Relato 1 - Thaís

\begin{tabular}{|c|l|}
\hline Relato & \multicolumn{1}{c|}{ Declaração } \\
\hline Relato 1 & $\begin{array}{l}\text { Foi a minha irmã que me alfabetizou né, eu aprendi a ler e } \\
\text { escrever com quatro anos[...]. E até hoje as pessoas elogiam ela, } \\
\text { até teve uma menina que mora perto da minha casa, ela diz que } \\
\text { é apaixonada pela minha irmã, então, todo mundo avalia, no } \\
\text { caso a escola da minha irmã, como sendo maravilhosa. }\end{array}$ \\
\hline
\end{tabular}

Fonte: Dados extraídos das entrevistas realizadas em 2014.

Conforme relato da entrevistada, é possível inferir que essas vivências possivelmente contribuíram para seu olhar afetivo sobre a docência. Além disso, a aluna citou situações com foco nas relações com professoras caracteristicamente afetivas ao longo de sua trajetória, refletindo e as reconhecendo como profissionais ideais, pois, além da docência, ofereciam indícios de amor e carinho para com ela e seus colegas. Quando indagada sobre suas antigas professoras, ela respondeu, de acordo com o quadro 4:

Quadro 4: Relato 2 - Thaís

\begin{tabular}{|c|l|}
\hline Relato & \multicolumn{1}{c|}{ Declaração } \\
\hline Relato 2 & $\begin{array}{l}\text { A profe (sic) Letícia eu lembro, o jeito dela, a responsabilidade, } \\
\text { é [...]. Que ela fazia tudo mesmo por amor, né. }\end{array}$ \\
\hline
\end{tabular}

Fonte: Dados extraídos das entrevistas realizadas em 2014.

Dessa forma, a imersão no campo familiar no momento da escolha da profissão pode ter sido vista pela agente como uma forma certeira de realização. Em seus estudos, Bourdieu (2001) indica, nestes momentos, possibilidades absolutas de alienação, já que trazem sérios riscos para o agente de ser continuamente levado a adotar o ponto de vista alheio, ignorando demandas de autonomia pessoal. 
Verificou-se uma primeira infância conturbada em razão de mobilidade territorial familiar e poucos laços de amizade, conforme apontado, anteriormente, no quadro 2. Para suprir uma lacuna observada na socialização primária (poucas interações satisfatórias no primeiro ciclo do Ensino Fundamental), constata-se que as atividades lúdicas pouco fundamentadas surgem para Thaís como ideais para a docência: frases como "a criança aprende brincando", sem muita explanação teórico-científica, foram recorrentes em suas entrevistas. Foi possível perceber, então, que aparentemente o acúmulo de saberes veiculados pela universidade não era priorizado pela aluna para sua futura profissão, que também recorria às práticas da irmã para se fundamentar.

Além disso, a discente citou o conhecimento de valores com o objetivo de dar sentido à vida das pessoas. Levando em conta um discurso religioso acentuado pela agente, essa percepção fez-se ainda mais significativa quando Thaís revelou-se membro ativo de determinada comunidade católica ${ }^{32}$. Ela frequentava a comunidade todos os dias da semana, era bastante envolvida com as atividades religiosas e estava aguardando a definição de seus superiores, pois gostaria de ser missionária (o que, segundo ela, precisava da aprovação do fundador da comunidade). A dedicação à igreja pareceu emergir como refúgio sentimental oferecido pela instituição às situações desagradáveis da infância, tão valorosas e marcantes sob o olhar da agente. Isto demonstra, também, a importância em considerar os aspectos da formação como um processo de desenvolvimento profissional docente, uma vez que esta profissão adquire, por vezes, também uma carga cultural originária de outros segmentos que não os aspectos voltados à área específica de formação.

De todo modo, são necessárias mais pesquisas para verificar mais minuciosamente como a afetividade e as questões relativas ao cuidado, e também, à religião, atuam quando relacionadas ao saber, em processos de formação docente.

\section{Afetiva e idealista: Sara}

Sara, ainda que tenha iniciado o curso com ambas as visões, demonstrou ao longo do tempo que a disposição afetiva atuou com maior força orientando suas escolhas, ligadas, sobretudo, à afetividade. De todo modo, pareceu estabelecer interação com questões técnicocientíficas da docência e do ensino.

No início do curso de Pedagogia, a aluna declarou se identificar com a área por gostar de ensinar e ajudar os colegas. Neste meio tempo, seu irmão foi diagnosticado com altas habilidades, sendo adiantado de classe na escola, o que, de acordo de com ela, estava tudo errado (sic), sob o argumento de que considerava o irmão inteligente, mas que isso o causou

$3^{2}$ A aluna era missionária em uma Comunidade Católica carismática, ligada ao que a Igreja Católica denomina Comunidades Novas. No Brasil, teve início em 1982, em Fortaleza - Ceará, e tem como principal missão a evangelização dos jovens, segundo preceitos da Renovação Carismática Católica. 
dificuldades em sua socialização. Sentiu-se intrigada e, quando surgiu uma oportunidade de iniciação científica na área, foi sua opção imediata, tanto como curiosidade, como para auxiliar a família nesta questão.

Verificou-se que a aluna, bem como sua família, posicionou-se de forma submissa às regras do sistema escolar. Esta colaboradora demonstrou uma busca por ser uma melhor aluna como forma de aumentar sua autoestima e encontrar uma identidade que pudesse a representar e, assim, constituir um capital simbólico. Segundo Bourdieu (2003), este capital surge como forma de elucidar a existência humana. Mesmo sendo produto da subjetividade, o poder produz para o agente a possibilidade de avaliar a concordância entre as estruturas sociais e as estruturas incorporadas, no caso de Sara, em sua trajetória de profissionalização.

Impulsionada pelo desejo de ser a primeira da classe, Sara demonstrou, ao longo das entrevistas realizadas, o intuito de ser reconhecida pelos professores e colegas da educação básica como uma aluna exemplar. Declarou que este sentimento aumentou após enfrentar bullying, uma perseguição de um colega durante o primeiro ciclo do ensino fundamental. Ao mesmo tempo, reconheceu o amparo da professora naquela ocasião, revelando traços de incorporação afetiva na construção de sua profissionalidade a partir da admiração pela docente que agiu como sua protetora.

Ainda que muitos professores do ensino médio tenham aconselhado a aluna a realizar uma escolha profissional distinta à Pedagogia, Sara levou em consideração o perfil da docente citada no parágrafo anterior. Possivelmente, o nível de influência desta profissional estabeleceu uma forte matriz de referência para composição de seu habitus.

Quando instigada a relembrar de alguns de seus professores, além da profissional acolhedora, a participante citou outra profissional com características afetivas, conforme quadro 5 .

Quadro 5: Relato 1 - Sara

\begin{tabular}{|c|l|}
\hline Relato & \multicolumn{1}{c|}{ Declaração } \\
\hline Relato 1 & $\begin{array}{l}\text { Uma professora de língua portuguesa, assim, a gente tinha uma } \\
\text { figura [...]. Ela era muito, como eu posso falar, uma pessoa que se } \\
\text { preocupava com você. }\end{array}$ \\
\hline
\end{tabular}

Fonte: Dados extraídos das entrevistas realizadas em 2014.

Por outro lado, foi possível perceber que a aluna não se limitava apenas à afetividade, mas manifestava e refletia o seu olhar sobre o ensino ao entrar em contato com professores do ensino superior. Sara trouxe à tona elementos incorporados por meio do curso de Pedagogia, como saberes voltados à interdisciplinaridade quando foi solicitada para avaliar seus antigos professores, como inferem os relatos no quadro 6. 
Quadro 6: Relatos 2 e 3 - Sara

\begin{tabular}{|c|l|}
\hline Relato & \multicolumn{1}{c|}{ Declaração } \\
\hline Relato 2 & $\begin{array}{l}\text { No Ensino Média também tinha uma professora, mas } \\
\text { também gostava do professor de filosofia, de química... Que } \\
\text { mesmo que eles não tinham essa coisa do carinho com o } \\
\text { aluno, gostava da forma que eles ensinavam, e assim, foram } \\
\text { professores que eu olhei de forma diferenciada. }\end{array}$ \\
\hline Relato 3 & $\begin{array}{l}{[. . .] \text { acho que essa professora de português do segundo ciclo }} \\
\text { do ensino fundamental, ela sim, talvez eu me espelharia, } \\
\text { porque ela sempre usava interdisciplinaridade, uma vez } \\
\text { produzimos uma palestra sobre prevenção de acidentes, } \\
\text { mesmo que era língua portuguesa, fazia teatro[...]talvez nela, } \\
\text { eu me espelharia em muitas coisas. }\end{array}$ \\
\hline
\end{tabular}

Fonte: Dados extraídos das entrevistas realizadas em 2014.

Para Bourdieu (2007a), o habitus se porta, também, como uma necessidade incorporada, transformada em disposição geradora de práticas coesas e que tem a possibilidade de fornecer sentido ao engendramento dessas práticas. Neste sentido, constatouse que a aluna refletia na busca pela coerência pedagógica conceitual, considerando válidas as práticas vivenciadas através de antigos professores à luz de novos saberes e representações possíveis.

\section{Ideal de transformação: Priscila}

Priscila, identificada com a visão transformadora, não apresentou oscilações demarcadas no decorrer de sua trajetória e nem motivos declarados para a escolha da docência para além de sua vontade em atuar como uma agente transformadora da educação.

Percebeu-se, na discente, uma submissão acentuada em relação à escola, especialmente no que se refere a professores marcantes. Foi perceptível a incorporação de elementos específicos sobre condutas ideais de professores da educação básica, como quando demonstrou possuir prazer em saber que era a melhor da classe no decorrer dos anos inicias, e também, a posterior busca incansável para atingir novamente a posição quando percebia estar em desvantagem, fatos que podem ter contribuído para a internalização de um requisito obrigatório para se auto satisfazer, construindo uma trajetória socializadora próxima ao idealismo e à busca pelo saber escolar socialmente valorizado e mais distante da afetividade.

Levando em consideração a incorporação constante de novos saberes, o que significa a ressignificação de seu próprio habitus, verificou-se que há potencialização sobre a disposição transformadora com a qual ingressou na universidade: se considera perfeccionista e reconhece suas dificuldades de aprendizagem, julgando contraí-las por falta de habilidade de sua professora do primeiro ciclo do ensino fundamental. Priscila evoca um discurso mais fundamentado em aprendizagens do curso de Pedagogia, tecendo críticas a alguns professores da sua escolarização básica, como apresentado no quadro 7. 
Quadro 7: Relato 1 - Priscila

\begin{tabular}{|c|l|}
\hline Relato & \multicolumn{1}{|c|}{ Declaração } \\
\hline Relato 1 & $\begin{array}{l}\text { Parece que eu fiquei com um receio muito grande dela (da } \\
\text { professora), justamente que muitas coisas que eu não consigo fazer, } \\
\text { podem ter sido fatores de que ela pode não ter me ensinado. Então, } \\
\text { eu tenho muita dificuldade, porque eu tenho essa dificuldade, tem } \\
\text { algum motivo, não é porque eu tenho alguma coisa em especial, mas } \\
\text { é porque eu não conseguia aprender, e às vezes eu culpabilizo ela de } \\
\text { certa forma. }\end{array}$ \\
\hline
\end{tabular}

Fonte: Dados extraídos das entrevistas realizadas em 2014.

Este relato trata de representar, na prática, a funcionalidade do habitus, destacando a sua capacidade de ser moldado de reestruturação em reestruturação, na medida em que outros saberes foram reavaliados pela aluna, sem desconsiderar percepções anteriores, mas sim, valendo-se dos mesmos como uma referência. Além de revelar justificativas originárias do prétreino, as reflexões da aluna reafirmam a coerência de se considerar a construção da docência como trajetória e não apenas uma fração de aprendizagem ocorrida de maneira aleatória.

Destaca-se, também, que a aluna valoriza professores com estratégias de ensino similares ao perfil que considera ideal, o que apresenta, neste caso, relações estreitas com a construção de sua identidade pessoal e profissional, conforme quadro 8.

Quadro 8: Relato 2 - Priscila

\begin{tabular}{|c|l|}
\hline Relato & \multicolumn{1}{c|}{ Declaração } \\
\hline Relato 2 & $\begin{array}{l}\text { Marcante mesmo foi esse professor de história, que por mais que ele seja } \\
\text { rígido, e tenha uma disciplina muito forte, foi um professor que eu gosto } \\
\text { da postura dele de ensino, então o mesmo professor da quinta, eu tive no } \\
\text { terceiro ano do magistério, então, ele trazia história para que você pudesse } \\
\text { intervir nela de alguma forma. O primeiro trabalho que ele pediu, era com } \\
\text { referência bibliográfica, então já era um professor que queria que você } \\
\text { fizesse uma pesquisa, e depois com uma apresentação crítica, que você } \\
\text { pudesse falar sobre aquilo, então isso eu gostava, porque ele agia de uma } \\
\text { forma que eu sabia que tinha que estudar porque eu queria conseguir fazer } \\
\text { aquilo bem. }\end{array}$ \\
\hline
\end{tabular}

Fonte: Dados extraídos das entrevistas realizadas em 2014

Marcelo Garcia (1999), baseado nos estudos de Zeichner (1993), faz uso de conceito de paradigma da formação de professores para se referir às matrizes de crenças responsáveis por oferecer características à formação docente. Nesta declaração, Priscila resgatou momentos do pré-treino, ao mesmo tempo que idealizou um perfil profissional professoral que fundamentou seus atos em perspectivas de autonomia, reflexibilidade, ordem e criticidade.

\section{Notas conclusivas}

No decorrer deste artigo, buscou-se apresentar e analisar, de maneira mais detalhada, a estreita relação entre o percurso da socialização, a escolha pelo curso de Pedagogia e a 
incorporação de elementos adquiridos a partir do acompanhamento da trajetória de três alunas, entre os anos de 2013 e 2014, em uma universidade pública do estado do Paraná.

Percebeu-se, nesta amostra, que não há uma busca claramente intencional de coerência conceitual para a escolha pelo referido curso. As colaboradoras são orientadas para desenvolverem estratégias a partir de um princípio gerador, seu próprio habitus. Sendo produto desse princípio, acabam por apresentar práticas orquestradas que corroboram umas com as outras, nem sempre realizadas de forma consciente. De acordo com Bourdieu (2007b), cada nova estratégia definida encontra tanto limites, quanto novos pontos de partida baseando-se nas estratégias anteriores.

Na concepção desta pesquisa, pode-se dizer, portanto, que a gênese da disposição docente encontra razão no interior da socialização primária, ou seja, é possível afirmar que o habitus de origem se articula à formação inicial, entrelaçando-se às histórias de vida das discentes. A forma com que a docência é aprendida e/ou desenvolvida apresentou, nesta pesquisa, relação estreita com os principais agentes socializadores primários, no decorrer da infância, no interior da família e da escola, estes que também se associaram a outros agentes socializadores, como igreja e grupos de convivência.

Ademais, entre incorporações e reestruturações, o habitus continuou, inclusive, no interior do curso de Pedagogia, atuando como um filtro permanente para novas aprendizagens (MONDARDO, 2016). Isto está em conformidade com os preceitos do desenvolvimento profissional docente, que ocorre, na prática, de maneira ampliada e perpassa diferentes momentos da carreira docente (MARCELO GARCIA, 1999; 2009).

Os dados analisados demonstram que os aspectos específicos das trajetórias das alunas, junto à escolha pela docência, atuaram como selecionadores de aprendizagens no decorrer do curso. A partir disso, considera-se que o conceito de habitus pode ser uma importante ferramenta para o adensamento das discussões relacionadas à amplitude e aos meandros do processo de desenvolvimento profissional docente.

É necessário aprofundar o olhar sobre as aprendizagens ocorridas nos percursos dos cursos de formação de professores, a fim de se compreender melhor as formas com que se manifestam, já que ocorrem de maneira contínua e em relação com diferentes agentes socializadores. Na contemporaneidade, a sociedade atual é caracterizada por múltiplas referencias identitárias (SETTON, 2002) e, nesse sentido, a formação de professores precisa ser mais bem esclarecida para ser efetiva.

De todo modo, pensar a socialização como trajetória (KNOBLAUCH; MONDARDO; CAPPONI, 2017) atribui sentido às ações desenvolvidas pelos sujeitos. Permite a nós, pesquisadores, mantermos acesos os desafios para compreender e encaixar os complexos fragmentos que permeiam a formação de educadores, e assim, contribuir para o avanço e melhorias globais na área da educação. 


\section{Referências}

BARDIN, L. Análise de Conteúdo. São Paulo: Edições 70, 2011, 229p.

BERGER, P. L; LUCKMANN, T. A construção social da realidade: tratado de sociologia do conhecimento. $25^{\mathrm{a}}$. ed. Petrópolis: Vozes, 1985.

BOURDIEU, P. Meditações pascalianas. Rio de Janeiro: Bertrand Brasil, 2001. . Esboço de uma teoria da prática. In: ORTIZ, R. (Org.). A sociologia de Pierre Bourdieu. São Paulo: Olho d'agua, 2003. p. 39-72.

Coisas ditas. São Paulo: Brasiliense, 2004.

. A distinção: crítica social do julgamento. Tradução: KERN, D; TEIXEIRA, D. Porto Alegre: Zouk, 2007a.

Futuro de classe e causalidade do provável. In: NOGUEIRA, M. A; CATANI,

A. (Orgs.). Escritos de Educação. 9a ed. Petrópolis: Vozes, 2007b. p. 81-126.

A Miséria do mundo. 8a ed. Petrópolis: Vozes, 2011.

FORQUIN, J. C. Escola e Cultura: a sociologia do conhecimento escolar. Porto Alegre: Artes Médicas, 1993.

JULIA, D. A cultura escolar como objeto histórico. Revista Brasileira de História da Educação. Campinas, n.1, pp.9-43.

KNOBLAUCH, A. Aprendendo a ser professora: um estudo sobre a socialização profissional de professoras iniciantes no município de Curitiba. 2008. 176f. Tese (Doutorado) - Pontifícia Universidade Católica de São Paulo, São Paulo, 2008. KNOBLAUCH, A.; MONDARDO, G. C.; CAPPONI, L. A. M. Algumas considerações sobre formação de professores e o habitus docente. Revista Diálogo Educacional, v. 17, n. 54, p. 1335-1351, set. 2017. ISSN 1981-416X. Disponível em: <https://periodicos.pucpr.br/index.php/dialogoeducacional/article/view/21949>. Acesso em: 07 dez. 2019.

LORTIE, D. C. Schoolteacher: a sociolgical study. Chicago: Univerty of Chicago Press, 1975 .

MARCELO GARCIA, C. Formação de professores: para uma mudança educativa. Porto: Porto Editora, 1999.

. Desenvolvimento profissional: passado e futuro. Sísifo - Revista das Ciências da Educação, n. 8, p. 7-22, jan./abr. 2009.

MARCELO GARCIA, C; PRYJMA, M. A aprendizagem docente e os programas de desenvolvimento profissional. In: PRYJMA, M. (Org). Desafios e trajetórias para o desenvolvimento profissional docente. Curitiba: Editora UTFPR, 2013. 
MARIN, A. J. O trabalho docente: núcleo de perspectiva globalizadora de estudos sobre ensino. In: MARIN, A. J. (Org). Didática e trabalho docente. Araraquara: JM Editora, 1996. p. 23-43.

MIZUKAMI, M. G. N. Docência, trajetórias pessoais e desenvolvimento profissional. In: REALI, A. M. M. R; MIZUKAMI, M. G. N. (Org). Formação de professores: tendências atuais. São Carlos: EdUFSCar, 1996. p. 59-91.

MONDARDO, G. C. Relações entre disposições do habitus de origem e formação inicial no curso de Pedagogia. 2016. 115f. Dissertação (Mestrado em Educação) - Setor de Educação, Universidade Federal do Paraná, 2016.

NUNES, J. B. C. A socialização do professor: as influências no processo de aprender a ensinar. 2001. 835f. Tese (Doutorado em Filosofia e Ciências da Educação) Faculdade de Ciências da Educação. Universidad de Santiago de Compostela, Santiago de Compostela, 2001.

PRYJMA, M. F. A pesquisa e o desenvolvimento profissional do professor da educação superior. 2009. 176f. Tese (Doutorado em Educação) - Programa de Pós-Graduação em Educação. Universidade de São Paulo, São Paulo, 2009.

SETTON, M. da G. J. Família escola e mídia: um campo com novas configurações.

Educação e Pesquisa, São Paulo, v. 28, n.1, p. 107-116, jan-jun. 2002. Disponível em: <http://www.scielo.br/pdf/ep/v28n1/11659.pdf>. Acesso em: 20 ago. 2014. A noção de socialização na sociologia contemporânea: um ensaio teórico. Boletim SOCED, Rio de Janeiro, v. 06, p. 01-20, 2008. Disponível em: < https://www.maxwell.vrac.pucrio.br/Busca_etds.php?strSecao=resultado\&nrSeq=11994@1>. Acesso em: 13 dez. 2015 .

. Teorias da socialização: um estudo sobre as relações entre indivíduo e sociedade. Educ. Pesqui., São Paulo, v. 37, n. 4, p. 711-724, dec. 2011. Disponível em: <http://www.scielo.br/pdf/ep/v37n4/ao3v37n4.pdf>. Acesso em: 10 jun. 2013.

TANURI, L. M. História da formação de professores. Revista Brasileira de Educação, Rio de Janeiro, n. 14, p. 61-88, ago. 200o. Disponível em: $<$ http://www.scielo.br/scielo.php?script=sci_arttext\&pid=S141324782000000200005\&lng=en\&nrm=iso\&tlng=pt >. Acesso em: 17 fev. 2014.

ZEICHNER, K. M. A formação reflexiva de professores: idéias e práticas. Lisboa: Educa, 1993 . 


\section{Biografia Resumida}

Giselly Cristini Mondardo Brandalise: Doutoranda em Educação pela Universidade Regional de Blumenau - FURB e integrante do Grupo de Estudos e Pesquisas em Educação Superior GEPES/FURB. Licenciada em Pedagogia e mestra em Educação pela Universidade Federal do Paraná - UFPR. Pesquisa processos de formação docente e internacionalização da educação superior.

Lattes: http://lattes.cnpq.br/3449580252501488

Contato: gmondardo@gmail.com

Adriane Knoblauch: Professora associada da Universidade Federal do Paraná - UFPR, com mestrado e doutorado em Educação pela Pontifícia Universidade Católica de São Paulo - PUCSP e estágio de pós doutoramento pela Universidade de São Paulo - USP. Pesquisa formação de professores, socialização profissional, práticas escolares e religião na perspectiva de Pierre Bourdieu.

Lattes: http://lattes.cnpq.br/2953309609222910

Contato: adrianeknoblauch@gmail.com 